\title{
El repentismo y la décima en la cultura peruana
}

\author{
The repentance and the tenth in peruvian culture
}

\author{
William Hurtado de Mendoza Santander ${ }^{1}$
}

\begin{abstract}
Resumen
En el presente estudio se asume desde la etnoliteratura, el andamiaje metodológico con el que se trabaja corresponde al diacrónico y al analítico interpretativo. La argumentación textual permite su desarrollo a partir de los estudios tanto del proceso de desarrollo del repentismo y la décima en Europa como el que tiene lugar en la cultura peruana y de aquellas de América donde se ancla y se reinterpreta con arreglo a las culturas donde la negritud aportó su espíritu ancestral.
\end{abstract}

Palabras clave: etnoliteratura; cultura peruana.

\begin{abstract}
In the present study it is assumed from the ethnoliterature, the methodological scaffold with which it works corresponds to the diachronic and to the interpretative analytic. The textual argumentation allows its development from the studies both of the process of development of repentismo and the tenth in Europe as that which takes place in the Peruvian culture and of those of America where it is anchored and reinterpreted according to the cultures where the Negritud brought his ancestral spirit.
\end{abstract}

Key words: ethnoliterature; peruvian culture

\section{Introducción}

La literatura peruana canónica, heredera de la tradición literaria hispana y nutrida por textos, escuelas y corrientes auropeas y amaricanas, ha mirado y con aires de superioridad y un gesto inocultable de desprecio a las literaturas producidas en lenguas nativas. Su visión hispanista la obligó a ser tributaria de una estética eurocentrista y, en consecuencia, alejada de los patrones de las literaturas ancestrales. La vigorización de los estudios culturalistas, principalmente los de orientación etnoliteraria van generado un enfoque paralelo.

La etnoliteratura como posibilidad de asumir la producción literaria de las culturas ancestrales y desde el principio de la otredad, propone reconocer y estudiar los discursos literarios por el otro. De esta manera reconoce un estatus de igualdad a las literaturas de los pueblos, por ejemplo, quechua aimara o de la diversidad amazónica sin que sus rasgos ideológicos, sociales, culturales o religiosos y mesiánicos permanezcan como elementos motivadores del discrimen estético.

No obstante, la etnoliteratura enfrenta todavía diversos desencuentros relativos por ejemplo, a las discordancias entre la teoría y la práctica. Como disciplina que tiene su objeto de estudio a los discursos literarios étnicos constituye un singular aporte para entender y apreciar lo estético del otro que, por lo demás tiene un peso histórico en la construcción del imaginario nacional.
Desde este enfoque teórico planteamos el repentismo del texto oral quechua con el wawaki y las expresiones actuales de la poesía, principalmente dialogada. Sostenemos, además que el repentismo y la décima cultura en América tiene, en la poesía oral de las culturas traídas de África el subtrato imprescindible para el posterior desarrollo de la décima.

En una primera parte hacemos un recorrido diacrónico que parte de los orígenes de la décima, considera las iniciales jarchas, la décima en la España que invade nuestro continente para, en los apartados siguientes centrar nuestro interés en el repentismo y la décima en el Perú y América.

\section{Materiales y métodos}

En razón a que el presente estudio se asume desde la etnoliteratura, el andamiaje metodológico con el que se trabaja corresponde al diacrónico y al analítico interpretativo. La argumentación textual permite su desarrollo a partir de los estudios tanto del proceso de desarrollo del repentismo y la décima en Europa como el que tiene lugar en la cultura peruana y de aquellas de América donde se ancla y se reinterpreta con arreglo a las culturas donde la negritud aportó su espíritu ancestral. La etnoliteratura, al estudiar los diferentes modos en que las culturas expresan su universo estético y se nutren de la tradición europea, imponen no solo el elemento sustancial

1. Profesor Principal del Departamento de Ciencias Humanas, Facultad de Economía y Planificación, Universidad Nacional Agraria La Molina, Lima, Perú. Email: william@lamolina.edu.pe 
de la poesía que es la metáfora y el ritmo, para inserntivar un nuevo espíritu. Cantan y poetizan sus formas de vida, sus representaciones míticas, sus relaciones con el mundo insular y el oleaje de sus mares. En su versificación están presentes tanto sus creencias como, sus recuerdos ancestrales y su presente que lo comparten en palabra, canto y danza con plantas y animales. En consecuencia, además de revisar el repentismo y la décima en España, lo hacemos en los territorios americanos que fueron receptores de las principales culturas africanas que ingresaron por los puertos para sincretizarse con las culturas nativas.

\section{Recorrido diacrónico}

Los orígenes de la décima se encuentran en la poesía oral improvisada $\mathrm{y}$, esta es una expresión universal de las diferentes culturas, sin distingo de continente, lengua o época. Esta universalidad, sin embargo, parece confundirse en una vorágine de nombres y de formas de expresión que va adquiriendo carácter particular en la historia cultural de cada pueblo. El repentismo, siendo tan antiguo como tan actual, es poesía oral improvisada y fue práctica permanente en la tradición griega, latina y provenzal como lo fue en la asiática, en el mundo árabe del que provienen frondosas influencias, y en el universo prehispánico de América. Nuestro territorio cultural constituyó una sementera extraordinariamente rica para la frutición de de la poesía que llegó de España y para su permanencia en la actual poesía oral.

El trovo de la España medieval como el que se cultiva, hoy en La Alpujarra, especialmente en Granada, Almería, Andalucía y, claro, en Canarias; los corrandes medrileños, el glossant de Mallorca y el vertsolario del País Vasco; la trova que, en Cuba, alcanza alturas estéticas extraordinarias constituyen expresiones de la poesía oral improvisada. El canto de competencia que conforman parte de los ritos esquimales, son poesía oral improvisada como lo son la payada argentina y uruguaya, la paya chilena o la poesía africana, particularmente la angolesa cuyo repentismo tendrá tanta presencia en los países de América Central y del Caribe y, también, de América del Sur.

De las diferentes expresiones poéticas de la América prehispánica, subsisten hasta hoy formas de la poesía oral y de la poesía oral improvisada que, construyendo desarrollos históricos diferentes, tendrán, sin embargo, igual fuerza para influir en la creación y tradición literarias de los siglos posteriores. Muestras de este vigor y esta persistencia se encuentran desde México hasta Chile y, claro está, en países como el nuestro donde lo andino y lo africano resultan parte sustancial de nuestro universo cultural y de nuestra actual personalidad.

\section{De las jarchas a la décima}

La décima es, quizá, una de las expresiones líricas que puede mostrar, sin cuestionamiento alguno, la solidez de un prestigio sustentado en la continuidad del tiempo y en la calidad y universalidad de sus cultores. Los orígenes de su vigencia temporal se remontan a la segunda mitad del siglo IV y al territorio cultural del mundo árabe donde la práctica de la improvisación poética está registrada en textos musulmanes tempranos, como afirma Bencheikh (1989). La tradición de improvisar versos y la práctica de competir a través de ellos es un camino ampliamente recorrido por los repentistas árabes desde iniciado el siglo VIII. Los poetas o creadores dictaban, entonces, sus composiciones a los trovadores o rapsodas para que estos los declamaran en las plazas y en las ferias.

La vertiente anónima, escrita en el primitivo romance de la actual lengua española, tendrá su más importante proyección en lo que constituirán, en su momento, los cancioneros, las coplas modernas y la décima. El primer cancionero en el que se reúne y ordena la producción literaria es el de Baena, nombrada así por ser su autor el escribano Johan A. de Baena. Hacia 1 440, recoge la poesía de los trovadores y poetas que, a fines del siglo $\mathrm{XIV}$, la expresan en diversas formas o especies como las cosantes (corrandes de hoy ), y las cantigas y, en las diferentes lenguas coexistentes en la Península: gallego, portugués, español, entre otras.

$\mathrm{Si}$ bien en este cancionero están recogidas creaciones de autores como Alonso Álvarez de Villasandino, Micer Francisco Imperial o Pero Vélez de Guevara; es la vertiente tradicional y callejera la que servirá de lecho a la corriente en la que se distinguen la trova, la copla, la décima o la posterior payada de frondosa estirpe. Los tercetos, cuartetos o quintetos rimados en octosílabos constituyen, sin duda, el antecedente formal o plano de expresión de la décima.

\section{La décima en España}

En párrafos anteriores hemos sustentado la importancia de la décima en su continuidad en el tiempo, desde las primeras formas de repentismo, expresión a la que le sirvió de soporte formal, hasta las posteriores tendencias como el culteranismo y el conceptismo y, a la universalidad de sus variantes culturales. La décima, como forma estrófica ya reformada y, en consecuencia, ya espinela, alcanzará su mayor resplandor al ser cultivada por los principales exponentes de la poesía, en la Historia de la Literatura Española, se denominó Siglo de Oro. Este período de tan excepcional desarrollo abarca, esencialmente, el Renacimiento del siglo XVI y el Barroco del XVII.

En este período, son cultores de la décima poetas como Garcilaso de la Vega, San Juan de la Cruz, Cristóbal de Castillejo, primero y, luego, Félix Lope de Vega y Carpio, Pedro Calderón de la Barca, Luis de Góngora y Argote, Francisco de Quevedo y Villegas, para citar a las voces mayores. Luego, la décima caerá en el olvido hasta la aparición de la Generación del 27, denominada por José Carlos Mainer (1983) la Edad de Plata. Entre 1902 y 1936 surgirán las extraordinarias voces de Jorge Guillén, Pedro Salinas, Gerardo Diego y aquellos poetas como Rafael Alberti, Luis Cernuda y Federico García Lorca, a quienes D. Alonso (1965) los ubica más cerca de los movimientos vanguardistas. 
Tanto los autores del Siglo de Oro como los posteriores de la Generación del 27, tendrán marcada influencia en la décima de América, claro está, en dos momentos distintos. El primero, en los orígenes y, el segundo, en su revitalización, sobre todo, en el campo de los contenidos.

\section{El repentismo y la décima en América}

La extraordinaria pasión y dedicación con la que se habla, canta y escribe la décima en América Latina y el Caribe, ha dado lugar a diversos textos y a diversas explicaciones. Muchas de estas han asociado la décima a una expresión de la negritud y solo a ella, dando lugar a la corriente denominada negrismo que se extendió desde el Caribe. Aquí encuentra apoyo la equivocada idea de que la décima es la estrofa propia del negro que creció en América y, como consecuencia, claro, razón para la estigmatización a la que está sujeta.

Otros prefieren estudiarla a partir de su rancia hispanidad $\mathrm{y}$, por tanto, centran su interés en su legado y herencia, de su inocultable influencia de la poesía culta y, en el cómo de su proceso de criollización o mestizaje. Los hay, y muchos, que al advertir su espíritu popular y muchas veces campestre, como en el caso de Las Antillas, adoptan una posición, más bien, desdeñosa. Junto a estos últimos $\mathrm{y}$, en el mismo tono, se encuentran aquellos que, sujetos a las exigencias de la literatura canónica y oficial, prefieren ignorarla y marginarla.

En estas muchas opciones, sin embargo, pocos se aventuran a explicar el porqué de tal pasión y la razón de la fruición con que se la cultiva. Uno de estos autores es el canario Maximiano Trapero (2009), asume el punto de vista diacrónico para responder a la interrogante relativa al porqué del desarrollo que ha alcanzado en América. La explicación es histórica y, en todo caso, es exofórica; por tanto, externa a la décima. Señalar que la décima llega a América traída por los emigrantes y misioneros españoles $\mathrm{y}$, más tarde por los marinos de los barcos que acodaban en los puertos de Vera Cruz, Panamá, Cuba, o Santo Domingo con su carga de negros congoleses y angoleños, no es una explicación suficiente del hecho externo.

Creemos que la vigencia y la vitalidad de la décima en América, a punto de haberse convertido, como sostiene Díaz-Pimienta (2009) en la "estrofa nacional" de países como Cuba, agregaríamos también de Panamá o Puerto Rico, se explica por la confluencia de dos poderosas corrientes: hispana, la una y nativa o americana, la otra. Si bien el caudal que han formado ambas corrientes ha dado lugar a otra, la actual, que sin ser ya ni la hispana ni la nativa, sino otra que se explica por la concurrencia de ambas. Una aportó el molde y su estructura de espinela, su cultismo y el prestigio de sus más importantes cultores; la otra, le insufló su alma americana, su canto nativo, su poesía prehispánica, su historia de cadenas y exterminio, su condición de explotación y muerte, su queja; pero también, su fuerza, su lucha y su esperanza. La décima de América es la estrofa en la que concurren versos y ritmos hispanos, prehispánicos y africanos, especialmente angoleses y congoleses.
De este caudal han surgido las extraordinarias voces de Los decimistas de los siglos XIX y XX de América Latina y el Caribe, entre ellos, Juana Inés De la Cruz, Guillermo Cházaro Lagos, Hidalgo, Zenem Zeferino, Gilberto Gutiérrez, Constantino Blanco Ruíz, Carlos Martínez, Leopoldo Bravo, Jorge Peña, Zarina Palafox (México); Luis Palés Matos, (Puerto Rico), Rubén Darío, (Nicaragua); José Franco y Eddy Omar Ruiz, (Panamá) José Martí, Nicolás Guillén, José Lezama Lima, Cintio Vitier, Manuel de Zequeira, M. Justo Rubalcaba, Gabriel De la Concepción Valdez, Juan Cristóbal Nápoles Fajardo, Jesús Orta Ruiz, Alexis Díaz Pimienta, Tomasita Quiala, Ruperto Limendoux, Martha Orube, Omar Mirabal, Emiliano Sardiñas, (Cuba); Juan Morales Ramos, José Gumersindo Torres (Puerto Rico); Medardo Patricio Mañón, (Santo Domingo).

En este conjunto nos importa la décima en Cuba, no solo por haberse constituido en la expresión de la cubanidad o del cubanismo que se inicia en el criollismo histórico del siglo XVIII, sino por ser, hoy, la voz de un pueblo que, como dicen Rafael Alberti y Nicolás Guillén es "la más verde primavera de los mares antillanos" que "va triunfante tras las huellas de Martí". Con lo anterior queremos decir que la tradición decimística cubana constituye un paradigma para los demás países, incluido el nuestro. El repentista Díaz-Pimienta (2009) dice que la décima cubana es "el molde perfecto tanto para sus quejas como requiebros sentimentales, como para sus cantos de dolor, de denuncia social o de simple narración cotidiana con carácter festivo, satírico, burlón, lúdico o circunstancial",

El cultivo de la décima cubana a partir del siglo XVIII tiene dos grandes vertientes: primero, la oral, cantada o repentista y, la escrita que, más allá de las tipificaciones de poesía de la africanidad o negritud, de la hispanidad o de la ruralidad y de la urbe, son grandes corrientes que permanecen hasta la fecha, con una infinidad y calidad de voces que, justamente, sostienen su naturaleza de paradigmática.

Si bien se puede afirmar, sin vacilaciones, que Espejo de Paciencia de Silvestre de Balboa Troya y Quesada, siglo XVII y, El príncipe jardinero y fingido Cloridano, del cubano Santiago de Pita, siglo XVIII, constituyen los dos grandes pilares sobre los que Cuba construirá su posterior literatura, no se puede dejar de mencionar nombres como Manuel de Zequeira y Arango que escribe La ronda, con décimas irónicas y festivas y, Manuel Justo Rubalcava, autor de Vivir muriendo, con décimas de un lirismo fino y un tono insistente que logra a través de la sistemática repetición de la palabra inicial. Como afirma Gutiérrez (2010), la influencia de Justo puede advertirse en autores más recientes como Téllez Espino, Juan Manuel Herrera o Domingo Mesa Acosta.

Ya en el siglo XIX destacan autores como Francisco Poveda y Amenteros, fundador de la tendencia criollista de la literatura; José Jacinto Milanés, Joaquín Lorenzo Luaces, José Joaquín Palma, José Fornarís, fundador 
de la escuela denominada siboneísmo, tendencia romántica que responde al propósito de crear una poesía de reafirmación nacional que exalte al indio con una intención política. Su máximo exponente, a no dudarlo, es Juan Cristóbal Nápoles Fajardo. En la actualidad, éste es considerado como el decimista más importante del período prenaborista. Se caracteriza por crear un lenguaje propio para la décima cubana. El corpus lingüístico con el que arma sus décimas proviene del campo donde nació y se crió, de allí que sus versos estén hechos con sememas referidos a frutas, aves, ríos y montañas que le dan a su lenguaje un color local con el que hace un pareado con el español culto.

A Nápoles Fajardo que, escribió con el seudónimo de Cucalambé que, según Gayol (1964), es un ingenioso anagrama de Cuba clama, le bastó un solo libro, Rumores del Hormigo, y algunas décimas sueltas, por crear "poesía de un güajirismo sincero y un siboneísmo fervoroso" que lo convierten en uno de los dos más importantes poetas y decimistas de la historia cubana. En su poesía, caracterizada por llevar lo más auténtico del espíritu del campesino y del negro a la décima, se encuentran también verdaderos pregones en defensa de su territorio. A este respecto, Tamayo (1976) dice que el Cucalambé no fue un campesino fingido, ni canta como un campesino ni desde el campesino; sino que fue un campesino culto que escribió y cantó tal cual fue.

En el siglo XX, Jesús Orta Ruíz, llamado el Indio Naborí, será la voz de la Cuba de nuestros días. Junto a él, tres voces poéticas que, por su importancia, no se pueden dejar de mencionar: Agustín Acosta que, con sus décimas relativas a la zafra, lo antecede; Eugenio Florit, cantor de la palma en Trópico y, Adolfo Martí Fuentes, uno de los impulsores de la décima irregular y autor de Décimas truncas, Puntos cardinales. Naborí, qué duda cabe, el más importante y el más poeta. Su calidad y su trascendencia dividen la literatura cubana en dos grandes ciclos: pre y postnaboriana.

Orta Ruíz, autor de Estampas campesinas, Bandurría y violín, Guardarraya del sueño, entre otras muchas como Décima y folclor ha construido su poesía con un andamiaje estético particular. En sus estrofas hacen dúo el canto hispano y el son del lenguaje popular alcanzando aquella musicalidad y esa excelencia formal que convierten su décima, tanto como su repentismo, en una de las cumbres más altas de las letras cubanas. Con Jesús Orta Ruíz, el Indio Naborí, dice Díaz-Pimienta (2009) "surgió y llegó a su más alta expresión con una revolución estética que lo convierte en un punto de referencia polisémico: temporal, técnico, temático y estilístico”. Para Gutiérrez (2010) sus décimas son "como aguijones de palma alfilereando estrellas".

La décima del Indio Naborí no solo encuentra consonancia la absoluta identificación con el alma del poblador de la tierra cubana, sino con el pasado que sujetó sus pies y el futuro que los ala en libre recorrido del mar a la montaña. $\mathrm{Su}$ décima es, en este sentido, poesía que reafirma la conciencia del pueblo cubano y, al mismo tiempo, el canto de una gesta que ha hecho de la Isla "una gaviota libre".

En esta parte del continente, los repentistas más cercanos son: Bernardino Guajardo, Rosa Araneda Orellanas, Daniel Meneses, Patricio Miranda Venegas, José Vicente Salazar Rojas, Isaías Angulo, carlos Díaz Loyola, Lázaro Salgado Aguirre, Violeta y Roberto Parra, o Enrique Dintrans Alarcón(Chile); Alfredo Zitarrosa, Carlos Molina, José Silvio Curbelo, Carlos Molina, (Uruguay); Rafael Obligado y Ortiz, Hilario Ascasubi, Estanislao Del Campo, Pedro Bonifacio Palacios, valioso no solo por su extraordinaria poesía, sino, por proponer modificaciones especiales a la décima con estructura de dos cuartetos y un pareado, (Argentina); Moreno, Venidlo Castillo, (Colombia); Andrés Eloy Blanco, (Venezuela), José Regato Cordero, Nelson Estupiñán B. (Ecuador), Francisco de Paula Del Castillo Andraca y Tamayo, Mariano Melgar, José Bernardo Alcedo Reluerto, Abelardo Gamarra Rondo, José Santos Chocano, Carlos y Porfirio Vásquez Aparicio y Nicomedes San Cruz; (Perú) son, entre otras, las voces más importantes de las generaciones pasadas.

Todas ellas tienen una vigorosa raíz nativa. Sus voces, más allá de su designación como repentismo, trova, payada, paya, vaguada, wawaki décima $\mathrm{y}$, al margen que estén duadas con guitarra, vihuela, tres, requinto o cuatro, quena, pinkuyllu o wankar, son la expresión de una América diversa y cuya tradición e historia nos hace única.

Gayól Fernández, tras señalar que con esa innovación la décima gano en frescura y versatilidad y fue, en consecuencia, más rítmica y más musical, afirma que, no obstante, la décima de los siglos posteriores asume diversidad de combinaciones tanto métricas como rítmicas.

Claro está que no se trata solo de ropajes, sino, muchas veces, de su propia estructura. La rigurosidad del octosílabo, modificado en Puerto Rico, por el verso de seis sílabas dando lugar a la "decimilla"; la pausa después de los versos pares y, en muchos casos, el cambio de su obligatoria rima consonantada por la asonantada, como es frecuente en una autoridad como lo fue Nicomedes Santa Cruz, o el desdén de la construcción obligada de la décima de pie forzado que asume Mariano Melgar, nos permiten dar cuenta no solo de su versatilidad, sino, de su dialéctica.

Lázaro Salgado Aguirre en su A la Pinta (1987) da cuenta de su vida a través de 143 décimas libres, al igual que sus compatriotas Violeta Parra y Pablo de Rokha (1964) y, Roberto Parra, en Décimas de la Negra Ester, han utilizado décimas libres. Se denominan libres cuando el autor desarrolla un tema a través de muchas décimas que pueden llegar a ser decenas o centenas. Las décimas son sueltas cuando son únicas y sus contenidos son, también, independientes. Estas son las más adecuadas cuando el improvisador, versador, o declamador requiere 
de una presentación, de proponer el desafío poético o de, acabada su participación, de la despedida.

La que alcanzó mayor reconocimiento es la de pie forzado, llamada así por la sujeción obligatoria a su estructura y forma. Se la conoce, también, como décima con planta o mote. Se caracteriza por tener una cuarteta o copla que no solo determina el contenido, sino, que debe ser glosada obligatoriamente en cuatro décimas y una despedida. Se denomina de pie forzado porque cada uno de los cuatro versos de la cuarteta debe ser el décimo verso, o verso final de cada décima. Es la preferida para las controversias, desafíos o duelos de los improvisadores.

Hay algunas variantes de esta décima y se las conoce con nombres diferentes: la letrilla o de línea obligada o punto que, se caracteriza porque todas las décimas deben tener como décimo verso, el verso que se haya escogido. Una muestra de esta es la de Isaías Angulo (Chile, 1886) que aparece en la antología hecha por Huapaya Amado (2007). Junto a esta se cultivan la redoblada donde el segundo verso es construido al revés del primero, como sugieren estos primeros cinco versos: Como el ave altiva / altiva como el ave /nativa alma que sabe / que sabe alma nativa / del dolor de ser cautiva.

Tan frecuentes como las anteriores son, aquellas en las que el décimo verso de la primera décima debe empezar la segunda décima, razón por la que se la conoce como encadenadas o enlazadas, las esdrújulas que obligan a que las palabras finales de los diez versos sean esdrújulas. Las denominadas de cabo roto que, según opinión generalizada, son las de más marcada influencia de la poesía oral africana, obligan a recortar una sílaba de la palabra grave en la que termina el verso y, convertirla de esta manera, en palabra aguda: Mi tradición es andí (na) Iy es mi palabra natí (va).

De esta sujeción a la forma y, aquí coincido con el cubano Gayol Fernández. se originan no solo la marginación de la décima por las literaturas canónicas, sino, los cuestionamientos referidos a su calidad literaria, su subordinación a la descripción y otros que serán tratados más adelante.

\section{La décima cantada}

La afirmación de que la décima, desde sus orígenes, fue una forma poética cantada y bailada, como lo fue toda la poesía antigua; no obstante, el riesgo de la generalización, resulta correcta. Fue cantada la poesía portuguesa, celta, latina, árabe y griega de la tradición homérica y sobre todo la de los cantus gestualis que constituyen los genes de los cantares de gesta y de los romances que, dicho sea al paso, constituyeron la expresión poética de los siglos XII a XIV. La tradición poética de la América prehispánica no constituye excepción y, por el contrario, su persistencia sostiene nuestra afirmación.

Los diez versos de estructura octosilábica y rima, preferentemente consonantada de nuestra tradición, no solo es el resultado de un largo proceso de transculturaciones; sino del ensamblaje natural del verso y la música de las diversas culturas que la integraron como forma de su expresión. La décima cantada del siglo XVI, viva hoy en Andalucía, Granada, Cartagena, Murcia, Valencia, Islas Canarias, el País Vasco, gran parte de los actuales territorios de Italia, Portugal y Cerdeña, constituye solo parte del ramaje que se hace fronda, espesura, en América y el Caribe.

Respecto a la décima cantada en España, Esquenazy (2008) tras sostener la existencia de variantes regionales como los bertsolaris del País Vasco, el trovo, de Murcia, Granada y Málaga; los albores, de Valencia y la que se canta al estilo cubano en las Islas Canarias, sostiene que "todos los géneros donde se cantan las décimas y las quintillas integran bailes que remiten al fandango" Con respecto al origen de esta expresión, la investigadora cubana dice que algunos remiten a Venezuela y México del siglo XVII. En la actualidad se emplea la décima como texto y se acompaña con la vihuela que, en aquella época, fue creada con caparazón de armadillo por el indígena Justo Rodríguez Nixen. Otros investigadores ubican su origen en Portugal del siglo XV como derivado del fado.

Como fuere, América canta la décima. La canta de modo diferente y acompañada de diversos instrumentos. En el Perú, en la costa central y en la costa norte, la décima cantada, según Santa Cruz (1982), se denomina socavón, tanto el texto como la melopea que la acompaña En los últimos años se viene trabajando en el landó. La afirmación de Esquenazi Pérez de que la décima cantada se denomina triste en el Perú nos parece inexacta. El triste, en proceso de desaparición en la costa central y norte del Perú, es una variante nominal del antiguo harawi prehispánico que subsiste de un modo vital en el yaraví del mundo andino, particularmente, en los actuales departamentos de Arequipa, Ayacucho, Cajamarca, Cusco y, en Junín y Pasco, bajo la forma de la llamada muliza. Sus prolongaciones se encuentran en el pasillo del norte peruano y en el ecuatoriano y colombiano.

La décima cantada en Argentina, en Tucumán y La Rioja, toma el nombre de tono, triste o payada; En Bolivia, décima; en Brasil, pajada y bancada; en Chile, paya, el verso y tonada; en Venezuela, galerón; en Uruguay, payada, décima y estilo; en Ecuador, décima y glosa, en Colombia, décima, guabina y torbellino. En los países que se ubican más al norte, como Panamá, la décima se canta como mejorana o socavón (v), por los instrumentos del mismo nombre con los que acompañan los campesinos sus décimas, además de mesano o maulina; en Puerto Rico, seis; en Santo Domingo, mediatuna; en México, décima jorocha, calentana y arribeña.

En Cuba, donde según Samuel Feijóo, citado por Posada (2003) la popularización de la décima española fue la primera nacionalización que por cuenta propia hizo el pueblo cubano, es el punto guajiro o punto cubano que se acompaña con tres, laúd y guitarra y, en algunas ocasiones, (información personal) hacia las zonas rurales, con bongó, claves y tumbadoras. 
Por su trascendencia importa insistir en la payada, no solo como décima, sino por ser poesía oral de extraordinaria raigambre y por su vinculación con la poesía oral quechua y andina. La zona de su mayor desarrollo es el sur de América, particularmente en los territorios ubicados en ambas márgenes del Río de la Plata: Argentina y Uruguay. Su influencia se proyecta hasta el estado de Río Grande do Sul, en Brasil; parte de Paraguay y Chile.

Los antecedentes de "lo gaucho" en las márgenes del Río de la Plata, Uruguay, se remontan al siglo XVII con la proliferación de las estancias y los peones que trabajaron en ellas. A estos peones los portugueses, a partir del siglo XVIII, los llamaron "gauchos", término con sentidos peyorativos como/malhechor/, /bandido/, /ladrón/, / carneador/ etc; en Argentina, el gaucho aparecerá en el siglo XIX con características diferentes. El argentino es errante como el Santos Vega de Hilario Ascasubi, es alzado o prófugo de la justicia como el gaucho Martín Fierro de José Hernández, resultado histórico de las luchas contra la tiranía de Juan Manuel de Rosas.

Si bien Martín Fierro se convierte en un paradigma donde la libertad y la justicia constituyen ideales vertebradores, el lenguaje popular, sentencioso, con versos que sintetizan sabiduría en dichos y refranes, se tornará en el lenguaje literario del gaucho de los años posteriores, educado y leído como Juan Moreira, de Eduardo Gutiérrez o Don Segundo Sombra, de Ricardo Güiraldes.

Como sostiene Dorra (2007), el antecedente más lejano se encuentra en la obra de Bartolomé Hidalgo (Montevideo, 1788) considerado como el primer poeta gauchesco. Desde entonces, la payada, como canto del payador o como contrapunto entre dos se ha constituido en el elemento central de la cultura y la literatura gauchesca. Son célebres las payadas que tuvieron lugar en 1884, en Montevideo, entre Gabino Ezeiza y Juan Nava y, en territorio argentino, entre los payadores José Betinotti y Francisco Biana (1913).

Vendrán, luego, los payadores que continúen con esta tradición en los países de ambas vertientes del Río de la Plata. Las voces y las guitarras de Carlos Molina, Gabino Sosa Benitez, Cayetano Daglio, Higinio Cazón, Francisco Bianco, son representativas. Entre los payadores que mantiene viva la tradición hoy, se encuentran, entre muchos con igual valía, José Curbelo, Héctor Umiérrez, Santiago Clares, Elbio Gurí, Juan Carlos Barrientos, Mariela Acevedo, Walter Mosegui, Wilson Saliwonczky, Gustavo Guichón, Carlos Machesini, Luis Barrionuevo, Manuel Rosa, Juan de Nava, Gabriel Luceno, Carlos Sferra, Jorge Alberto Soccodato, Catino Arias, Marta Suint, Mónica Sosa, María Susana Repetto y Lilina Salvat.

Respecto a la payada (pajada) de Brasil, se debe precisar que, no solo es la proyección de la tradición argentina y uruguaya, sino, el resultado de una corriente literaria conocida como nativismo que surge aparejada a los movimientos nativistas o emancipadores del siglo XVIII y comienzos del XIX. La importancia de las Guerras dos Mascates y Guerra de Emboabas en Minas Gerais, radica en la vigorización de la identidad nativa de Brasil. Según Afranio Coutinho (1968), "el nativismo literario es un sistema semiótico, que al contacto de una tierra nueva, debe inventar su lengua en relación a un sistema semiótico específico".

En el estado de Río Grande do Sul, las payadas o bancadas, son cantadas en décimas o espinelas que se acompañan con guitarras. Nombres como Jayme Caetano Braun o Paulo de Freitas Mendonça, junto a Jadir Soares Oliveira, Antonio Costa, Aral Cardoso, Crioulo Batista, Adao Bernardes, Pedro da Fontoura, Rafael Teixeira Chiapetta, Juca Moraes; son los payadores que hacen que la trinidad voz, guitarra y décima, sigan vivas.

En Chile, la paya es una expresión decimística propia del campesino de la zona central. Si bien Lázaro Ligorio Salgado Aguirre es el payador contemporáneo más reconocido, se recuerdan entre sus antecesores, al Mulato Taguada y Javier de La Rosa por el contrapunto o duelo que sostuvieron en 1830. Dentro de los payadores más reconocidos se encuentran Pedro Yáñez, Eduardo Peralta, Leonel Castro, Miguel Ramírez, Antonio Contreras, Dángelo Guerra, Leonel Sánchez, Jorge Céspedes, Víctor Emiliano Quintana, Guillermo Villalobos y Fernando Yáñez.

Al amparo de lo anotado para la poesía gauchesca, se puede considerar al gaucho Santos Vega, del libro del mismo nombre, de Rafael Obligado como el primer payador y, en el caso del Perú, a José Manuel Sojo, alias Matalaché, célebre por su repentismo y el contrapunto o desafío que sostuvo con Nicanor De los Santos Seminario, alias Mano de Plata, en la novela de Enrique López Albújar, ambientada en la costa norte del Perú.

\section{El repentismo y la décima en el Perú}

La décima en nuestro país no puede constituir una excepción de lo que hemos señalado respecto de la producción decimística de América Latina y del Caribe. Siendo parte del conjunto, tiene también las mismas vertebraciones: la heredad proveniente de la Península, la riqueza del aporte ancestral nativo y el que llega en el barco negrero desde el África. Como en los demás países, encuentra expresión en la oralidad y el repentismo, en el canto, así como en la formalidad de la escritura. No obstante, tiene también, particularidades, tanto en su diacronía como en sus diversos momentos sincrónicos. Una de ellas se refiere a lo que llamaremos décima andina, no solo por el especio geográfico en la que se produce, sino, por la influencia que ejerce el peso cultural andino, aun cuando la forma, décima de pie forzado, por ejemplo, sea hispana.

Respecto a lo andino, es pertinente precisar que se encuentran formas particulares de repentismo en la cultura quechua. El caso más ilustrativo lo encontramos en el antiguo wawaki, expresión poética dialogada en la que participan hombres y mujeres. Una muestra de ello constituyen los wawakis cusqueños: 


$\begin{array}{ll}\text { Qhari: } & \text { Warmi: } \\ \text { Llaqtaytaraq risaq, } & \text { Suyallawanqa } \\ \text { kharutaraq risaq } & \text { munallawanqa } \\ \text { kutimuspañas } & \text { ninkichu; } \\ \text { munakunaypaq } & \text { imas nuqa suyaykiman } \\ \text { apasqayki... } & \text { mana imayuq maqt'ata... }\end{array}$

La propuesta que hace el varón al irse a su pueblo de que la espere para luego, a su retorno, llevársela para quererla, es rechazada con el sustento de que esperar a un hombre pobre "que no tiene nada", es ilusión. En el siguiente, el diálogo es menos tenso. Ella indaga por la opinión de la madre respecto al poncho que le ha dado y, el responde con nativa ironía de que "si está tejido con paja, no hay problema que se lo ponga":

Warmi:

Qari:

Imanintaq mamayki

Ichhuchamanta

punchitucha

\section{kaqtinqa}

churasqaymanta, churakuypas niwanmi phallchaschay, t'ikachay... sumaq hawas t'ikachay...

En las festividades de los pueblos andinos del Perú, Bolivia y Ecuador, en sus fiestas religiosas, se encuentra enraizado y ha encontrado su expresión en los cantos del carnaval con formas diversas como las matarinas, genuinas expresiones del repentismo en Cajamarca; las cumananas, en Piura y las wifalas en el espacio surandino.

\section{El contexto}

En lo que refiere propiamente a la décima, esta se cultiva en el Perú desde el siglo XVI en las principales ciudades andinas del antiguo Virreinato del Perú, particularmente, en Cusco, Quito, Cajamarca, Arequipa y La Paz. A partir del siglo XIX, su residencia se trasladará a las ciudades y ámbitos rurales de la costa, a cuyo espacio, finalmente, se va relegando. Tal situación alcanza explicación no desde una inmanencia, sino desde un conjunto de condiciones políticas, económicas, sociales y culturales que, finalmente, constituyen nuestra historia.

Si bien la década del 50 marca, en la mayor parte del territorio americano, el inicio del conjunto de reivindicaciones de los derechos del indio y del negro, dando lugar a un importante proceso de valorización de la indianidad y la africanidad, en el caso del Perú, este proceso deberá esperar el paso de los años y los gobiernos. De allí que nos importe las referencias a la década anterior. Los gobiernos de Manuel Prado y José Luis Bustamante i Rivero, signados por los efectos del Frente Democrático, el Contrato de Sechura, la sustitución de las Juntas Municipales Transitorias que, en el fondo seguían siendo las Juntas de Notables, como anota Chirinos (1991). La situación real del indio no cambió en nada y, la del negro, siguió su proceso de ingreso y asimilación al lado hispano; sin embargo, los discursos los aludían con la frecuencia y la facilidad de las promesas.

En el gobierno del general Odría, el de la coalición, caracterizado por la ausencia total de programas e ideales, el indio y el negro siguen abandonados a su suerte, aunque entre la suerte del uno y el otro, haya serias diferencias. Una dictadura de improvisaciones astutas como afirma Tamariz (1995) en las que se anulan las libertades constitucionales y, en su lugar, se promulga la ley de Seguridad Interior de la República a cuyo amparo se persigue, encarcela y expatria; no podía ofrecer ninguna posibilidad para que la marginalidad del indio y el negro pudieran acceder a la cultura y la política nacionales. Al indio le fue negada la escuela, la salud, el derecho, el pensamiento, la opinión y la palabra. El negro encontró la forma de burlas el cerco. Como consecuencia, las olas migratorias de los Andes hacia Lima no solo darán lugar a una incomodidad y repulsa de la aristocracia y oligarquía radicadas en la capital, sino, al inicio de un descontento social aun vigente y aun irresuelto.

El régimen siguiente, el de Prado, tampoco representa ningún cambio. A la crisis económica que marca este gobierno como reflejo de la norteamericana, se sumará la crisis moral que hereda del régimen anterior y se acentúa con la Convivencia. Si el indio y el negro tienen alguna importancia, está descansa en el interés de la mano de obra barata, cuando no gratuita, y en tanto los andinos sigan habitando en el arenal de Ciudad de Dios de ese entonces, y no perturben la fastuosidad de los bailes y el tiempo dedicado a los programas de televisión que se inician.

Los años siguientes, los de Fernando Belaúnde Terry, si bien se inician con un auroral "resplandor democrático" se caracterizarán, más bien, por continuar con la política de favorecer los intereses de empresas transnacionales y de un contado y tradicional número de familias que tenían el control de la economía nacional e invertían sus rentas en el exterior. En este resplandor se acentúan las migraciones y el crecimiento incontrolable de las barriadas. En los Andes, particularmente en el Cusco, el indio inicia la recuperación de sus tierras que el régimen de la hacienda les robó, proceso al que el gobierno denominará "invasión de tierras". Las consecuencias no se expresan solo en los datos fríos de la cantidad de indios muertos en Ninabamba, por ejemplo, sino en la aparición de las guerrillas que, según Béjar (1963) fueron el resultado de la profunda quiebra económica, social, política y moral del Perú.

El negro y el indio, debían esperar hasta la irrupcíon de Juan Velasco Alvarado, en 1968-1975. Su gobierno significó la interrupción de una continuidad donde la conducción política del Perú se alternaba entre anacrónicas aristocracias, oligarquías feudalistas y militarismos obcecados e inconsecuentes que, en conjunto, se sirvieron del Perú. Más allá de su declarada prioridad por los intereses nacionales, las reformas emprendidas y de los efectos de estas, se le reconoce el haber creado un espacio sociocultural para la participación de las "clases marginadas", particularmente para el negro y el indio. En este período, como sugiere Guerra (1994) al referirse al siglo XX, se acentúa la presencia provinciana que, en Lima, aumenta la presión sobre los grupos de poder y del gobierno. 
La incorporación del quechua como segunda lengua oficial, al margen de sus alcances en la minimización de la diglosia y la heteroglosia dominantes hasta entonces, tendrá efectos devastadores en el sentir, el pensar y el actuar del racismo de la sociedad peruana. Resultaba, simplemente intolerable, que el quechua se utilizara en la publicación del semanario Cronicawan, que la radio y la televisión, tan proclives al gusto de las clases dominantes, propaguen la palabra y el canto quechua y, a su vez, abrieran sus espacios a la palabra, el canto y la danza negra. Por primera vez el Perú empieza ver que su rostro es, también, cetrino, indio y negro y que su cultura no solo está conformada por la heredad hispana, sino por la presencia ignorada del indio y tolerada del negro.

En este contexto alcanza a expresarse lo indio con su taki, su wayñu y su danza y se hace más impactante el baile afroperuano con "Perú Negro," con su landó y su contrapunto. En forma paralela, la investigación y el estudio de las culturas marginales alcanzan un extraordinario desarrollo dando mayor empuje a la naciente andinística y a la explicitación de los aportes de la cultura negra en la formación de nuestra actual identidad. La expresión y la expansión dicimística será un proceso paralelo que, con Nicomedes Santa Cruz, alcanzará la cima más prominente.

En este sentido resulta legítimo señalar que Santa Cruz representa para el Perú lo que el Indio Naborí para Cuba o lo que José Hernández para Argentina; no solo por ser el creador más valioso de la décima, sino por ser el verdadero artífice del actual vigor y apogeo de la producción decimística peruana y, al mismo tiempo, de ser la demostración más palmaria de que las valoraciones racistas y estereotipadas no solo se sustentan en supinas ignorancias, sino, en concepciones estrechas y absurdas.

La décima y la poesía de Santa Cruz, no obstante su inicial marginación, tiene un extraordinario impacto en los diversos estratos sociales y en sus mentores culturales hasta alcanzar la valoración que lo consagra. Esta valoración, iniciada, en nuestro caso, por Sebastián Salazar Bondy (1964), Ciro Alegría (1966) y Estuardo Núñez (1981), será continuada por voces autorizadas como Otis Handy (1979), Romero (1988), Adrianzén (1998), Mariñez (2000), Ojeda (2003), Ngom (2006), Carazas (2010) entre otros muchos.

La obra consagratoria de Santa Cruz que, se inicia con Décimas (1960), tendrá verdaderos hitos con Cumanana. Décimas de pie forzado y poemas (1964) Ritmos negros del Perú (1971) y Canto negro (2004). Como en ningún otro autor, la presencia de la negritud, la ironía fina y dura, la musicalidad de su verso octosílabo, la destreza de su decimar y su capacidad para apartarse de la descripción, son en Santa Cruz una constante de poesía extraordinaria. Convenimos con Martha Ojeda (2004), cuando sostiene que la voz poética de Santa Cruz es singular porque es para el pueblo, se nutre del pueblo y de las tradiciones orales; no obstante, esta relación con lo popular no le resta valor literario a su quehacer poético.
En función de la temporalidad y de esa espacialidad ya señalada, proponemos dos momentos, que no corresponden, necesariamente, a lo andino y lo costeño de un distribución geográfica. Para la ilustración de ambos nos basamos en los datos de Huapaya Amado, (2007). El primero corresponde a autores nacidos en el "interior del país", como José Gabriel Aguilar y Narvarte, Mariano Aspiazu, Marcos Durán-Martel, (Huánuco); Mariano Melgar, Gabino Guillén, Pedro Ríos, Casimiro Torres y Fidel Zavala, (Arequipa); Ignacio Villavicencio, (Cusco), Abelardo Gamarra Rondo, El Tunate; Edelmira Lizarzaburo Leyva, Antonio Cavero Tirado, Walter Muñoz Vega, (La libertad ); Saúl Félix Ramírez Soto (Chiclayo).

Destaca en este grupo y, el precisarlo no rebaja en nada la obra de los otros, Mariano Lorenzo Melgar Valdivieso, trascendental no solo por sus odas, sus elegías y sus epístolas; sino y, sobre todo, por sus yaravíes en los que recoge el alma y el sentimiento andinos y los vierte en el molde clásico hispánico. En lo que respecta a la décima, este autor no solo se adscribe, por su calidad, a la rica tradición de los cultores del siglo de oro español, sino se muestra como un renovador de la décima de pie forzado. Se trata de la introducción de las composiciones que responden a la forma de cuartetas o redondillas y que serán glosadas en sus décimas. Unas veces glosa el primer verso de la cuarteta en el último verso de la décima, como es de ley, por ejemplo, en Nunca he sabido rezar y, otras, introduce una primera décima suelta y recién a partir de la segunda, glosa el primer verso de la cuarteta y va alternando décimas libres con aquellas en las que asume la glosa, como ocurre en: La espada de tu retiro.

Para la tradición decimística resulta una verdadera innovación la décima Contados tengo los días, donde los versos de la cuarteta o redondilla que deben glosarse como pie forzado, en el último verso de cada una de las cuatro décimas a las que da lugar, se glosan más bien como verso inicial. Aquí, como en sus yaravíes, advertimos este recurso que, a nuestro entender, proviene más bien de la poética quechua. Esta observación está anotada en Mariano Melgar. Poesías completas (1971).

El segundo grupo de decimistas jalonados por Francisco de Paula del Castillo Andraca y Tamayo que, según Huapaya es el más antiguo (1716); esta conformado por José Bernardo Alcedo y Mateo Chuecas Espinoza (1788); Manuel Ricardo Palma Soriano (1833); Emiliano Niño y Pastor (1845); Santiago Villanueva Cabezudo (1854); Carlos Germán Amézaga Llanos (1862); Pedro Delgado Mago (1870); Domingo V. Martínez Luján (1871); José Santos Chocano (1875); Carlos Vásquez Aparicio (1891); Adán Mora Rojas (1896); Marino Mendoza Yaya y Porfirio Vásquez Aparicio, verdadero hito marcador del decimar (1902); Juan Abelardo Leiva Zambrano y Eduardo Román Thomson (1905); Martín Adán (1908); Orlando Gonzáles García (1920); Javier Arturo Valera de la Cuadra (1923); Blanca Nava López (1925); hasta la aparición y el encumbramiento de Nicomedes Santa Cruz Gamarra (1925). 
En las generaciones posteriores a Santa Cruz se encuentran voces que tienen oficio y que por esa razón han sido incluidas por Huapaya Amado en la antología que reúne decimistas de Chile y Perú ( 2007). Estas son las de César Ferreyros Delgado y Fernando Ojeda Mendoza (1926); Juan Antonio Urcariegui García (1928); Germán Súnico Bazán (1929); Eleuterio Villón Flores (1931); Pedro Alberto Rivarola Urdanivia (1935); Gregorio Antonio Silva (1942), Manuel A. Ganoza Ramírez (1944); Angel F. Barrionuevo Spencer y Andrés R. Arriola Badaracco (1946); Oscar E. Vega Alvarado (1947); Mauro Mendoza Chacaltana y Víctor Hugo Parraguez Vásquez (1948). Las siguientes décadas están representadas por el propio Huapaya Amado (1950); Fidel Alcántara Lévano (1951); José Luis Mejía Huamán (1969); Víctor Augusto Rivas Plata (1970); Groffer Joy Rengifo Arévalo (1974) y Renato Cisneros Sánchez (1976).

\section{Conclusiones}

La décima, en nuestro país, como la poesía quechua o la creada en las lenguas ancestrales aún no ha logrado su pleno y franco ingreso al canon de las literaturas nacionales o, en todo caso, no ha logrado su cabal permanencia. Las razones que suelen esgrimirse para esta marginalidad no solo se alegan en América Latina y el Caribe, sino que se alegan y se sostienen desde fuera de la literatura, principalmente, y desde el interior de la literatura o desde la inmanencia. En el primer caso, tiene que ver con un racismo solapado que ve en la décima la expresión del negro y, en consecuencia, la de una africanidad que aún molesta la parte blanca de nuestra heredad. Emparentado con este absurdo sostén que, supone la décima como la expresión exclusiva de la negritud, está el de su ruralidad y el atribuirle la de ser su cultor. El peruano negro, como ya ha sido dicho, pudo escalar y acomodarse en el estrato blanco para encontrar en el "criollismo" su lugar y, en el campo, una actividad laboral y una remuneración. En uno y otro caso, subyace, además, la falsa oposición que se da entre lo culto y lo inculto, entre lo urbano o citadino y lo rural y campesino.

Desde el interior de la literatura, los cuestionamientos hincan en la inocultable tendencia a la descripción y, en consecuencia, a su falta de poesía. Ya Gayol Fernández se lamentaba señalando que "nuestras décimas populares constituyen, por lo general, prosa versificada y dominada por el artificio de la descripción". La calidad poética, siempre discutible y siempre susceptible a la mirada de tendencias y preferencias, tiene que ver con lo casi estrictamente coyuntural de su temática, con la práctica de una rima fácil, muchas veces pueril, ligera, que da lugar a inconsistencias e incompatibilidades en el contenido y, en consecuencia a un lenguaje de ausencias metafóricas.

La circunstancialidad ha convertido al decimista en un hábil y memorioso rimador, en un competente constructor de octosílabos. Al mismo tiempo, en un rápido buscador de consonancias que, lamentablemente, lo han alejado de la poesía de la que el octosílabo y los diez versos debieran ser tributarios. El resultado de esta circunstancialidad, muchas veces de un decimar por encargo o por lograr el aplauso fugaz de la concurrencia a una efemérides local, es el de las incompatibilidades de los significados y de los sentidos.

Entre las décimas de esta circunstancialidad, no faltan aquellas que abundan en la expresión "acriollada," en el chascarrillo fácil, en el verso bufo, en el doble sentido y en la connotación sexista. Tal práctica encuentra explicación en la búsqueda de la aceptación social y el ingreso al espacio cultural oficial, como un modo de romper la multiglosia que afecta nuestra producción literaria.

$\mathrm{Si}$ resultan aceptables estas observaciones, resulta legítimo, al cabo de este recuento de autores, preguntarse por qué Alma Fuerte, el Cucalambé o el Indio Naborí, Mariano Melgar o Chocano, Martín Adán o Nicomedes Santa Cruz devienen en verdaderas cumbres de la décima. Las respuestas pueden provenir de distintas perspectivas: en unos casos por convertir en verso la negritud, en otros, por exaltar la revolución y la patria y, en los demás, por hacer más intenso y más alto el sentimiento humano; pero $\mathrm{y}$, sobre todo, porque en todos ellos la poesía resulta lo más importante.

Más allá de estos apuntes, nuestro trabajo retorna la décima al espacio poético andino, la instala en la interferencia de dos sistemas semióticos, donde los sentidos y los contenidos se glosan en décimas libres. Siguiendo la secular tradición de la poesía oral, nuestro canto está presidio de una presentación y concluye con la obligada despedida

\section{Literatura citada}

Béjar, H. 1965. Las guirrilas de 1965: balance y perspectiva. Lima, PEISA.

Coutinho, A. 1968. La tradición afortunada. Universidade Federal do Rio de Janeiro.

Chirinos, E. 1991. Historia de la república. Tomo III. Lima, Brusa,S.A.

Díaz-Pimienta, A. 2009. Breve acercamiento a la historia de la décima y el repentismo en Cuba. Sociedad Suiza de Americanistas.

Dorra, R. 2007. El arete del payador. Revista de Literaturas Populares VII (1), UNAP, Puebla.

Esquenazy, M. 2008. La décima cantada en América Latina y el Caribe. Paideia Latina $N^{0}$ 3. CIELAC. Nicaragua.

Gayol, F. 1964. Teoría Literaria, Vol. II. Editorial Mediterraneo, Madrid.

Guerra Martiniere, M. 1994. Historia General del Perú. La República, Tomo IX. Edit. Brusa. S.A. Lima.

Gutiérrez, A. 2010. Hitos de la décima en Cuba. Periódico 26, Las Tunas.

Huapaya Amado, C. Salgado Aguirre, Lázaro.Taller Lican-Rumi. Lima. 
Huapaya, A.C. 1976. La décima en Chile y Perú. Homenaje a Lázaro Salgado Aguirre. R \& F Publicaciones y Servicios SAC. Lima, 2007. Mambí.

López, L. 1986. La décima cubana. Revista de Literatura Cubana $\mathrm{N}^{\circ} 4$. La Habana.

Mainer, J.C. 1983 La Edad de Plata. Gredos. Madrid, 1983.

Melgar, M.1971. Poesías Completas. Academia Peruana de la Lengua. Lima.

Ojeda, M. 2004. Prólogo a Canto Negro. Libros en red. Montevideo.

Posada, C. 2003. La décima cantada en el Caribe y la fuerza de los procesos de identidad. Revista de Literatura Popular III. Antioquia.

Santa Cruz, G.N. 1982. La décima en el Perú. Instituto de Estudios Peruanos, IEP. Lima.

Tamariz, L. D. 1995. Historia del poder. Elecciones y golpes de estado en el Perú. J. Campodónico. Lima.

Tamayo Rodríguez, C. Era el Cucalambé un campesino fingido?. Revista

Trapero, M. 1998. El libro de la décima. La poesía improvisada en el mundo hispánico. Universidad de las Palmas de Gran Canaria. 